\title{
Erratum to: The Moderating Effect of Perceived Organizational Ethical Context on Employees' Ethical Issue Recognition and Ethical Judgments
}

\author{
David Hollingworth $\cdot$ Sean Valentine
}

Published online: 28 January 2015

(C) Springer Science+Business Media Dordrecht 2015

\section{Erratum to: J Bus Ethics \\ DOI 10.1007/s10551-014-2088-9}

The last two sentences in the last paragraph of the Measures section, as it currently appears, read as follows:

Since prior research indicates (e.g. Randall and Fernandes 1991) that individuals' responses to research questions may be influenced either consciously or unconsciously by their desire to manage other's impressions in a positive way, social desirability (SD) was measured using a ten-item social desirability scale (Crowne and Marlowe 1960; Fischer and Fick 1993; Strahan and Gerbasi 1972). Items were coded so that higher values indicated stronger social desirability $(\alpha=.714)$.

The text should be modified as follows:

Since prior research indicates (e.g. Randall and Fernandes 1991) that individuals' responses to research questions may be influenced either consciously or unconsciously by their desire to manage the impressions of others in a positive way, social desirability (SD) was measured using a four-item subset of a ten-item social desirability scale (Crowne and Marlowe 1960; Fischer and Fick 1993; Strahan and Gerbasi 1972). The four statements included "I like to gossip at times," "There have been occasions when I took advantage of someone," "I sometimes try to get even, rather than forgive and forget," and "At times I have really insisted on having things my own way." Items were evaluated on a seven-point scale comprised of "1-Strongly agree" and "7-Strongly disagree," and values were coded and averaged so that higher scores indicated increased social desirability. The coefficient alpha of the scale was .703 .

Note: In addition, one of the observations for the social desirability scale was miscoded as a "7," when it should have been blank as the result of an item nonresponse. Since this miscode involved only one observation (for just one variable), the error did not significantly change the results or findings/hypothesis testing.

The online version of the original article can be found under doi:10.1007/s10551-014-2088-9.

\footnotetext{
D. Hollingworth $\cdot S$. Valentine $(\varangle)$

Department of Management, University of North Dakota, 293, Centennial Drive, Mailstop 8377, Grand Forks, ND 58202-8377, USA

e-mail: sean.valentine@mail.business.und.edu

D. Hollingworth

e-mail: david.hollingworth@business.und.edu
} 